\title{
THE RELATION BETWEEN MILITARY AND CIVILIAN ACTORS IN MILITARY OPERATIONS \\ Petr KOVANDA
}

\author{
University of Defence, Brno, Czech Republic, petr.kovanda@unob.cz
}

\begin{abstract}
Looking at the current ongoing conflicts in the world, we can likely state that future armed conflicts will cover not only the solution of combat actions, but increasingly these conflicts must be addressed in cooperation with civilian actors. Although five years have passed since the introduction of the new strategic concept of NATO, which is declared for greater cooperation with civilian actors and the implementation of crisis management through a comprehensive involvement of both civilian and military components together, there are still critical issues interfere with successful collaboration to solve problems in the crisis area. One of the most important representatives of civilian actors are a humanitarian organization. And only each other getting to know can eliminate mutual distrust and thereby improve the final effect of the solving of crisis.
\end{abstract}

Keywords: NGO, NATO, strategic concept, civilian actors, cooperation

\section{Introduction}

The current century is full of conflicts, whose character is fundamentally different from the wars which was taken place in first part of the last century. The classical conception of the war, when individual states fought against each other, and conflict resolution has been in the hands of individual Nations, becomes a thing of the past. Rising role of the new actors will characterize the future operational environment Those new actors will comprise the irregular enemy using irregular warfare, criminal organizations, NGOs, mass media, international organizations and civilian actors as part of a civil environment. For current and future crisis management, are all parties used the resources that the involvement of nonmilitary actors. A breeding ground for the use of these resources becomes a civil environment.

\section{Civil environment}

The war in the civilian environment is constantly during the whole history of mankind, because you cannot separate the local population from events that takes place at the point of conflict. What, for the armed forces represents the civilian environment? If we are going to be based on the definition of Civil-military cooperation (CIMIC), so the civilian environment is characterized by a set of involving the local population with their spiritual and civil leaders. In addition to this we have to assign governmental and nongovernmental organizations operating in the territory, both international and local. Another element with whom we must count they are the leaders of the civilian agencies, to protect the interests of multinational companies on the given territory. An example of such civilian agencies should be a civilian security agency, whose task is to watch over the technological equipment multinational company, or staff of the media agencies, whose main aim is to obtain reports from the crisis area. Each of these actors has, of course, in the area of operations of their interests that are trying to promote and thanks to this occurs more than once the excesses. 


\section{Comprehensive approach}

Since 2006, the UNITED NATIONS seeks a greater representation of civil actors in the crisis areas. This leads to an effort to create the concept of the approach to the solution of conflicts, both in the stage of their course, so then when its stabilisation. Finally, on the basis of this fact, the NATO Member States adopted at the Summit in Lisbon in 2010 a new strategic concept, in which the main point is striving for the use of the principles of the comprehensive approach to crisis management. The European Parliament adopted "Resolution of the European Parliament of 3 July 2003. April 2014 on the comprehensive approach of the EU and its impact on the coherence of the external action of the EU ". The main idea of the concept of a comprehensive approach contained in those documents, is the involvement of all actors, both military and civilian personnel in crisis situations. Their targeted use would lead to escalation of efforts leading to re-establish functional standalone company. There is mutual support of the both components. However, these ideas are very difficult to implement in practice. There is no consensus between the participants and coordination function is often pushed into the background of the comprehensive approach, for the different interests of the various actors.

\section{The relations between the civil and armed forces}

Above we have defined actors contained in a civilian environment. If we focus on solving problems directly in the crisis area, so from this group, we can set aside the three most prominent leaders and define the relationships between them and the army.

- The civilian population.

- The humanitarian organization.

- Civilian agencies.

\subsection{Relations with the civilian population}

The local population since the arrival of coalition forces in particular are expected to improve their life situation. However, when does not come the improvement of living conditions and you will rather worsen, posing in front of a group, which endorse the presence of foreign troops on own territory. A bad situation, it gives them the opportunity to embrace the population on your side against the coalition forces. To come into contact with the civilian population are determined by the unit of the civil-military cooperation (CIMIC). Their job is just to induce trust between the civil and the Commander of the unit. Gain the confidence is a long-term process, which can be disrupted by any offence to members of the armed forces that is unacceptable in the eyes of the local population. These events often occur from ignorance cultural, religious and social rules that the company adheres to. And just disregard local practice the armed forces, can lead to fatal consequences that will cause, that originally the friendly population become the enemy. Enemy that will be hard for us to identifiable, because they can assimilate among the civilian population. Coalition troops then loses the support of the local population, and although it may seem that won an important battle, so in fact they lose the entire war.

\subsection{Relations with humanitarian organisations}

On the far more complex level is the relationship of the armed forces with civilian organisations, dealing with humanitarian activities in the area of operations. Activities of the civilian organizations covers a wide range of activities, starting with humanitarian aid, protection of human rights and minorities, the care of refugees and ending with the restoration of the basic sectors of the State such as health care, agriculture, education, local administration and self-government. The advantage of the humanitarian organisations is, they often work in the area of crisis long before the situation escalate so far, that was required the intervention of the armed forces. Thanks to this, humanitarian organisations are far better able to move between the local people and local authorities and establishing relationships is far more feasible for them. Knowledge of the local environment allows 
them to recognize deteriorating living situation of the local population and thus increase the discontent of far earlier than it will be able to register members of the armed forces.

In the framework of crisis management on the basis of the principle of a comprehensive approach, would just humanitarian organizations should be one of the main stakeholders of the civil environment, with members of the armed forces should cooperate most often. However, it faces a lot of contentious points, which is then excluded any form of cooperation or very difficult. These points include:

- mutual lack of knowledge of capabilities

- mutual lack of knowledge of the work processes and the planning process

- inflexibility of military forces

- distrust of the misuse of information for reporting purposes

- the unwillingness to share the results of joint work

- slowness of the planning process of the armed forces

- maybe swapping with a member of the humanitarian worker's armed forces

When we generalize negative statements from civilian actors, representatives of humanitarian organizations, [1] so their views is the idea, that the armed forces are very cumbersome. This leads often enough to, if these organizations can, so the desired action perform yourself. The armed forces are, in the opinion of humanitarian organisations, the only hurdle in their work. Quite often we meet with an opinion, the armed forces want to take the work of humanitarian organisations and that they want their activities so-called humanized. Change this unflattering picture of the armed forces in the eyes of civil organizations will not be easy. On the other hand, unfortunately, we must conclude, that even the leaders of the armed forces are the willingness to cooperate with the humanitarian organizations. For many the commanders are NGOs source of problems that undermine the implementation of their operational task. The members of humanitarian organizations often enough nor are they willing to inform the Commander of the unit that will move in his area of responsibility.

This common negative attitude leads to misunderstanding and reluctance to cooperate with each other and the solution of possible common tasks is, therefore, quite often in the context of non-standard relations, when individuals know each other from previous cooperation and are willing to cooperate. Commanders of units that come on the valuable information from the civilian environment, which could help them to perform the tasks. Another negative aspect of this position is greater cost of the mission, for reasons of duplication of capacity.

\subsection{Relations with the civilian agencies}

Other participants, which we must not forget, are members of the civilian agencies. If showbiz units dealing with the protection of important objects, who have their tasks strictly defined, so we can't overlook the staff of public and private intelligence companies. Thanks to information technologies, we have the ability to keep track of individual conflicts, almost in live with all the negative consequences. Messages that show us the destitute populations as a result of combat activities carried out by the armed forces, the company perceives very negatively and, therefore, opinion about the armed forces becomes negative for this reason. To eliminate this preview, cooperation with the media, should be implemented already representative of the higher levels of command and permeate all levels.

\section{Intelligence information}

For the solution of the current conflict more and more from the military point of view takes on the importance of the ability to collect information, their analysis and subsequent application. However, when contact with the civil environment intelligence gathering is a very sensitive issue. Firstly, we must conclude one main principle. Each soldier is an observer and, 
therefore, a source of information of the civil environment. He can provide the intelligence authorities, certain pieces of information that create a coherent common mosaic image. With the civil environment, in addition to units specially designed for collecting the information, meet the members of units of the civil-military cooperation (CIMIC) and Psychological operations units (PSYOPS), so their information obtained are far more extensive. But we have to remind you, these units, only the information collect. It is not the task of these units evaluate information outside its scope. The intelligence assessment of the information obtained from the civilian environment is a matter of another folder.

As I wrote above, one of the biggest sources of information from the civilian environment can be humanitarian organizations. Here again we must pause to consider the idea of a comprehensive approach conflict resolution and involvement of these organizations in this concept. Solving problems in the context of a comprehensive approach requires the sharing of information. However, it faces many barriers. Some organizations have within its Statute Regulation that were not associated with any party to an armed conflict in order to ensure their impartiality. Another barrier is the lack of confidence that comes from bad experience, which mostly resulted from mutual ignorance of the procedures and options. This leads to mistrust communicating information with the notion that information will be used ultimately against them or against their sources of information.

On the other hand, in a reciprocal exchange of information by members of the armed forces should inform humanitarian organizations about potential security risks resulting from ongoing operations. Even this, however, faces several barriers. We definitely must not share information about an upcoming or ongoing operation because of its secrecy from the enemy. And this in turn leads to the creation of some walls between civilian actors and humanitarian organizations, if within the operations of a humanitarian worker comes into conflict with the armed forces.

\section{Conclusion}

In conclusion, we can say that, though mutual cooperation and the connection of civil and military capacities for crisis management, would have been beneficial for all actors, however, it is implementation seems very ungainly. Members of the armed forces should understand the sense of civilian actors and the same thing can be said about the civilian actors. The change in the mutual access and therefore the possibility of future cooperation and coordination tasks in current and future operations, it will be possible to realize after the mutual knowledge of the capabilities and options.

\section{Refrences}

[1] Interview carried out with representatives of NGO's - International Conference HUGO 2011, Prague

\section{Bibliography}

Kovanda, Petr a Pavel Zona. Cimic in the picture of NATO's new strategic concept. In:The 18th Internacional Conference, The Knowledge-Based Organization. SIBIU, Rumunsko: "Nicolae Bălcescu" Land Forces Academy, 2012, s. 82-85. ISSN 1843-6722

NATO's new strategic concept Available from http://www.nato.int/strategicconcept/pdf/Strat_Concept_web_en.pdf (19 November 2010)

AJP - 3.4.9: Allied Joint Doctrine for Civil Military Cooperation. NSA, 2013

Pikner, Ivo; Galatík, Vlastimil. Future operational environment and military concepts. In: The 16th International Conference The Knowledge-Based Organization management and military sciences. Sibiu, Rumunsko: "Nicolae Bălcescu” Land Forces Academy, 2010, p. 157162. ISSN 1843-6722 